\title{
III. On the fracture of colloids
}

\section{Frederick Guthrie}

To cite this article: Frederick Guthrie (1879) III. On the fracture of colloids, Philosophical Magazine Series 5, 8:46, 25-29, DOI: 10.1080/14786447908639647

To link to this article: http://dx.doi.org/10.1080/14786447908639647

$$
\text { 曲 Published online: } 13 \text { May } 2009 .
$$

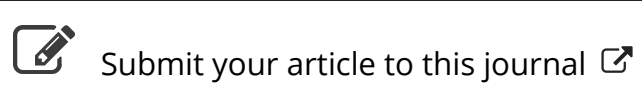

\footnotetext{
Џlll Article views: 2
}

Q View related articles $₫$ 
were differently hard in opposite directions, so that they were more easily scratched in the sense $\mathrm{AB}$ than $\mathrm{BA}$; and if they possess one such unilateral property, they must surely have others. One surely ought to expect that a current driven through a pyroelectric crystal from analogous to antilogous pole would heat it, and that a current in the reverse direction would cool it, or heat it less. If, however, as I begin to fear, this is a wrong scent, I should be very grateful to any one who will kindly point the fact out.-OLIVER J. LoDGE.

\section{On the Fracture of Colloids. By Frederick Guthrie*.}

[Plates II. \& III.]

$\S 1$. PROMINENT property with regard to solid colloids A is that they have neither crystalline form nor planes of cleavage. When such a body is broken it offers the socalled conchoidal fracture. An agglomeration of crystals may present in mass the conchoidal fracture usually associated with colloids. This is the case with granite, and eminently so with basalt, all of whose constituents are crystalline. When the solid has resulted from the intersolution of two or more crystalloids it may, like glass, present the colloidal fracture in a most marked manner. And, indeed, even single crystals themselves are often subcolloidal in fracture; that is, conchoidal fracture accompanies the crystalline. This state is shown by the diamond, sugar-candy, quartz, \&c.

I assume here that every cohesionally homogeneous mass of solid matter will break conchoidally when subjected to pressure sufficient to cause fracture.

\section{Experiments.}

$\S 2$. The cracking of a glass plate by pressure offers no special features of interest. A round plate placed on a thick soft cloth and pressed in the centre by a round cork cracks radially ; the cracks are generally slightly curved. Fig. 1 show's two examples of fracture of crown glass by pressure in the centre. Similarly, if a round sheet of glass placed on a thick soft cloth be pressed down at its circumference by means of cardboard rings, the same class of crack is produced; for, indeed, the two conditions are essentially identical.

$\S 3$. The internal strain caused by difference of temperature causes fracture of great regularity and beauty. It rarely happens that a sheet of glass of any shape breaks into only two pieces when heated. If a circular piece of "crown",

* Read before the Physical Society, March 22, 1879. 
glass, about $3 \frac{1}{2}$ inches in diameter, be loosely balanced horizontally between the lips of a wooden clip and brought with its centre over an air-gas burner so that the top of the flame is about an inch below the glass, the latter almost invariably cracks at least into three pieces; and when the pieces are three in number they as invariably have the form shown in fig. 2 .

The remarkable symmetry of each of these, and their similarity to one another, show that the shape is not an accident of the glass. The constant features are (1) that the two main cracks join before reaching the circumference, (2) that there are in each crack, reckoned from this confluence, three concavities towards the centre of the circle, the first being nearly straight, (3) that there is a little kick given by the crack as it leaves.

Out of sixty-four specimens of fracture produced under these conditions ten showed this species of two-crack fracture. The shapes of the cracks are perfectly similar to those given; and the symmetry is sometimes such that the side pieces may replace one another after inversion so perfectly that it is scarcely possible to tell that they are misplaced.

$\S 4$. The same method of heating may result in the production of a great variety of forms; but they are all derived from the above type. In fig. 3 are shown a few of the more simple.

The three-crack figures $(a, a)$ are about as frequently formed as the two-crack figures. I find eight of the threecrack out of sixty-four similarly treated specimens. Perfectly similar forms were got when the plate was laid on a retort-ring or supported on three corks and heated in the same manner. A special series of experiments was moreover made to see if the position of the clip had any influence upon the attitude of the crack. In figures 2 and 3 the mark $\dagger$ shows where the plate was held. As to the effect of the position in the original sheet of glass of the pieces experimented on, as determining the attitude of the axis of cracking, the following examination was made. Six pieces having been marked as they lay in the sheet, forming a radial band, were cut out and heated as above. The apex of crackage always appeared somewhere on the semicircle which was towards the centre of the sheet, but varied in this semicircle so considerably that it is at present doubtful whether the position in the sheet influences the crack-axis. Fig. 4 shows the amount of variation; the point of the arrow represents the apex of the crackcurve. The lower figure represents the original sheet and the positions of the several pieces in it. 
$\S 5$. If the sheet of glass be made very much larger, or the flame smaller and more pointed, another alteration of the crack-figure ensues. The apical point of the previous figures advances into the sheet; and this is followed by a fan-like cracking of the glass between the apex and the still nearest circumference. In fig. $4, a$ shows the cracking of a plate of crown glass, 9 inches in diameter, over an air-gas burner; $b$ is a $5 \frac{1}{2}$-inch-diameter plate similarly treated. In $c$ we have a plate of crown glass, 3 inches in diameter, which was laid on a cloth and heated from above by a fine blowpipe-flame. If we conceive what was before called the apical point to reach the centre, the heat fracture would become approximately the central-pressure fracture, namely radial.

$\S 6$. A piece of plate-glass $\frac{1}{4}$ inch thick and a little over 7 inches in diameter, cracked when heated in the centre over an air-gas burner, as shown in fig. 5 a. A piece of "sheetglass" (Chance's), 3 inches in diameter, cracked as shown in b. A slab of resin $\frac{1}{2}$ inch in thickness and $3 \frac{1}{2}$ inches in diameter, heated in the centre by a jet of low-pressure steam, gave the fissures shown in $c$. Square porcelain tiles cracked nearly straight across in one crack.

$\S 7$. Pieces of crown glass of various shape were next examined, with the result which declares itself in fig. 6 . The pieces were supported at the point marked $c$, and the flame applied below the point marked $\dagger$.

The figure 6 shows that the same general type is preserved. It instructs us that the apical point seeks one of the nearest points of the circumference.

$\S 8$. Experiments were next made for the purpose of ascertaining under what circumstances, if at all, a crack could cross a crack. A circular plate of crown glass was cut by the diamond in concentric rings, and the crack was made to pass, by tapping, completely through the thickness of the glass, around the whole circumference. Such divided glass on being heated in the centre over an air-gas burner cracked according to the same type as before. Sometimes the heat-crack would run across the diamond-crack, as though the latter had no existence. Sometimes the heat-crack would follow, and, as it were, adopt the diamond-crack, and then break off. In the latter of such cases the inner circle may be suffering a threecrack fracture, while the outer ring exhibits only a two-crack fracture on the converse. Fig. $7(a)$ exhibits the former circumstance, fig. $7(b)$ shows the influence of a greater number of concentric cracks.

$\$ 9$. The heating of the central part of a circular plate 
should give the same crack-figure as the cooling of the circumference ; and, as a matter of experiment, it is found that the figures are very similar. In order to cool the circumference of a heated circular plate with some approach to uniformity, an annular trough was constructed by cementing concentrically two glass cylindrical vessels of the same depth but different diameters, one inside the other, and over-filling with mercury, so that the convex surface of the metal projected. The glass was held in a wooden clip widely stretched, so that the axis of the clip being vertical the plate was horizontal. Held, when uniformly hot, inmediately above the mercury, it was let drop and pressed down in the middle by a piece of wood. The fracture is in this case instructive; for while in fig. $8(a)$ the old type got by heating the centre is resumed in $b$ and $c$, the fracture is either influenced or even accompanied by the circular fracture along or near the line of greatest temperature-difference.

$\S 10$. It is clear that heating in the central regions should produce a similar fracture to that brought about by cooling around the circumference, and cooling at the centre a similar fracture to that caused by heating the circumference.

On heating a circular plate at the circumference by means of a "rose" air-gas burner, it breaks with far greater violence than when fracture is produced by central heating. The parts are scattered at least three times as far in the former as in the latter case. The form of the fracture is essentially radial; but the fragments, even when the primitive type is widely departed from, present wonderful symmetry. A noticeable point in this fashion of fracture is the invariable appearance of two pieces on opposite sides of the centre whose form is approximately rectangular ; that is, their sides are halfcords instead of radii. This forn suggests that there are two chief centres of maximum fracture, and that the bounding radii of the two systems are parallel. In fig. 9 the pieces marked a represent these singular pieces. Out of seven plates which have been broken in this way, there is not one in which this feature is absent.

$\S 11$. As to cooling a hot plate in the centre, $I$ find snch extreme difficulty in reproducing the inverse conditions of heating a hot plate at the circumference that I have rarely succeeded in reproducing the same type of fracture.

Also it is seldom the case that a sheet of glass cracks during heating at its edge. More frequently a sheet of glass which has been heated at its edge cracks when cooling. The crack then appears to follow that isothermal line along which there 
is the greatest difference of temperature at right angles to the line.

\section{Remarks.}

$\S 12$. About the fracture by mechanical strain it may appear to satisfy many that the lines of fracture are perpendicular to that resultant of the pressure which lies in the plane fractured. A tear in a sheet of paper is at right angles to the two opposing pressures, or rather to their resultants at the point yielding.

What is a crack? Which are its beginning and end ? In only one of the above-cited experiments can the growth of a crack be followed. In $\S 11$ when a plate heated at the edge has refused to crack while being heated but cracks on cooling, the crack is seen to extend from the edge of the plate inwards, following, generally speaking, a semicircular path, but sometimes curiously modified towards the centre of the curve.

A crack is neither a line of least cohesion nor a line of greatest strain. Nor is it a line where $\frac{c}{s}$ has a series of minimum values. The more perfectly elastic a medium is, the more fully does the crack resemble a flash of lightning or wisely laid railway-line, and the more it departs from the river-course or the descent of a globule of mercury down an inclined but undulating surface. Its path is the curve whose course is determined by the integnal of $\frac{c}{s}$ being a minimum. The sudden splitting through of the solid æther by the electric discharge furnishes us with figures by no means remotely resembling those of the fracture of glass. Even or rather especially the forms of fig. 4 remind us of this.

As to the typical form in fig. 2, it has been suggested by my brother, Mr. Charles Guthrie, that this form is a compromise between the circular line of fracture along some isothermal line where the difference of temperature is greatest, or rather the difference of expansion is greatest, with the three lines of relief which would be radii at angles of $120^{\circ}$ with one another.

This is a very suggestive hint; but, for reasons sufficiently apparent from the foregoing, it is insufficient. 
Phil. Mag.S. 5.Vol.8.Pl:II.

Fig. 1.

Fig. 2.
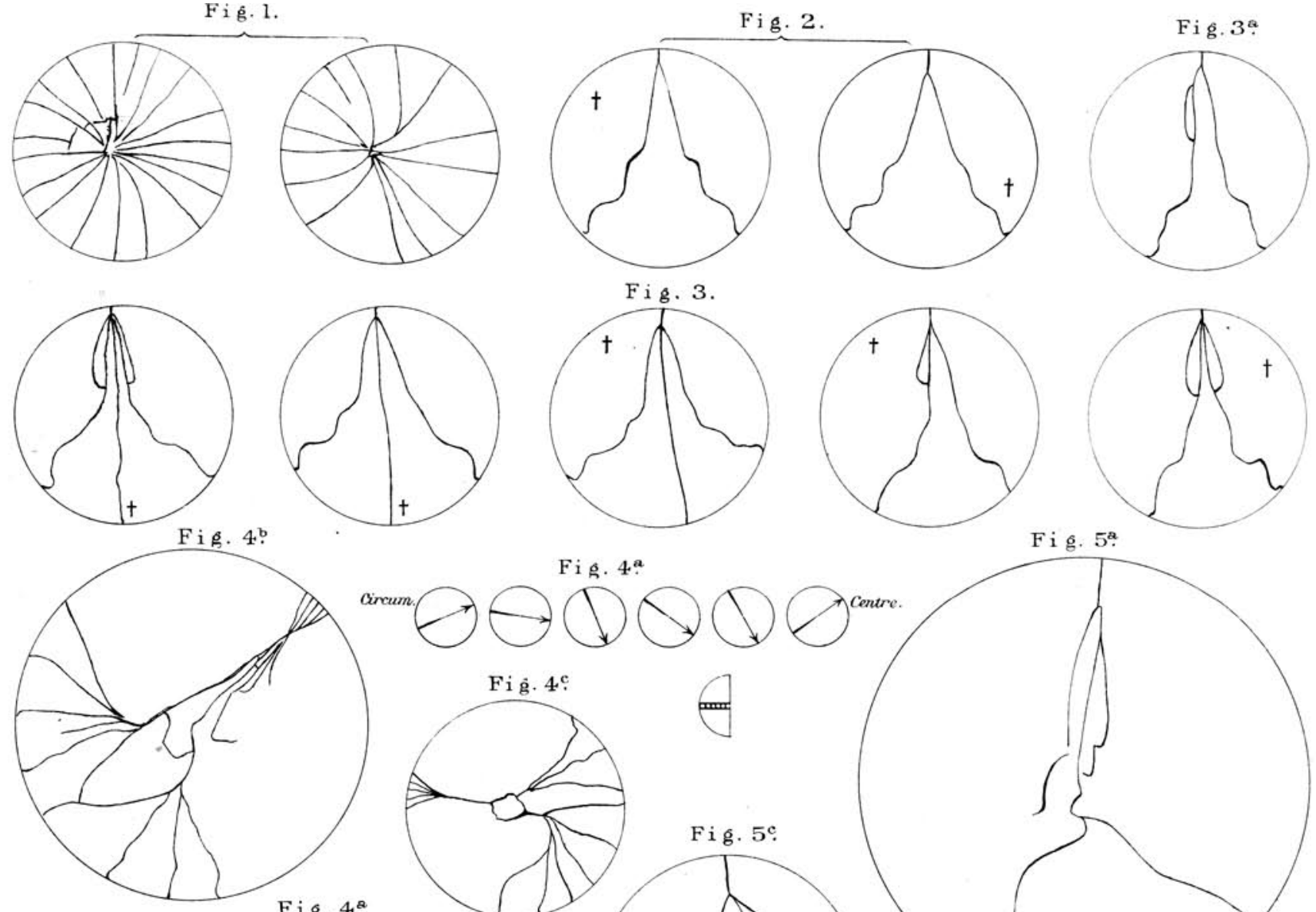

Fig. $4^{a}$
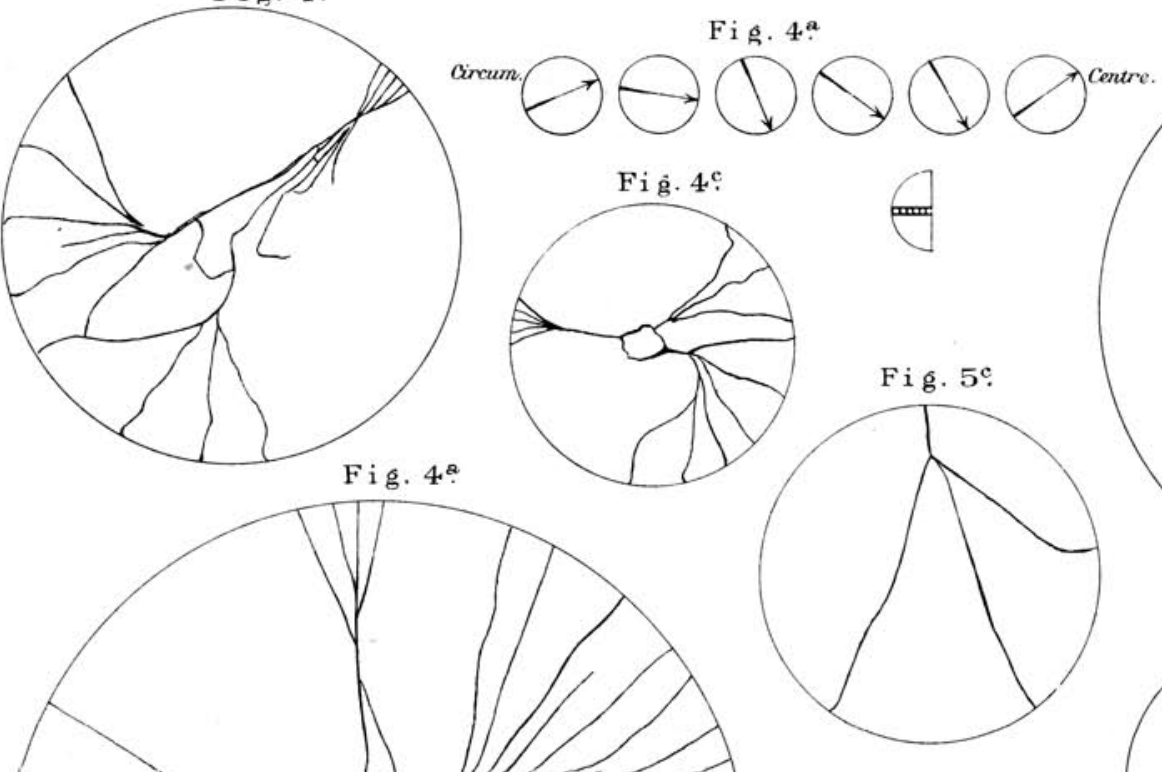

4
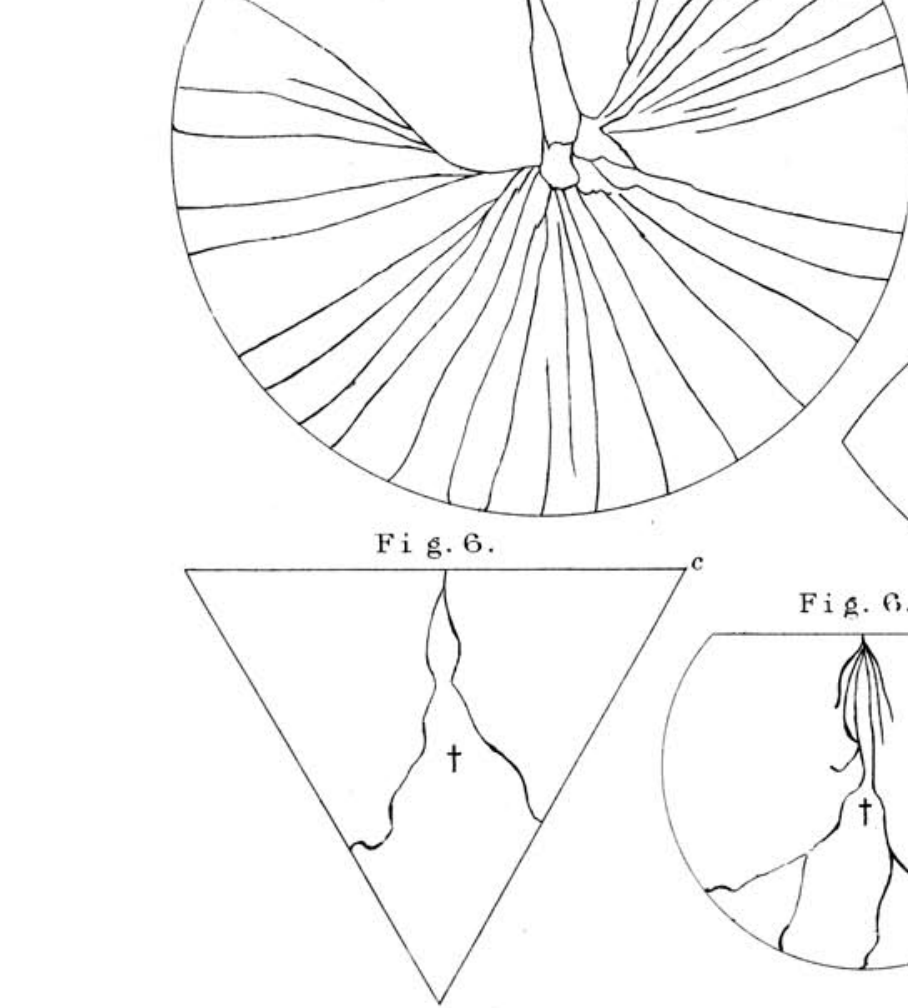

Fig. 6.

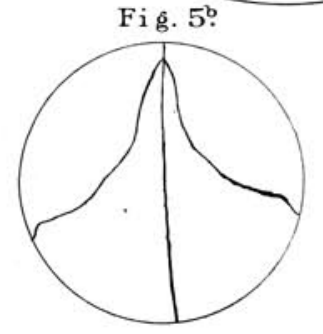

Fig. $5^{a}$.

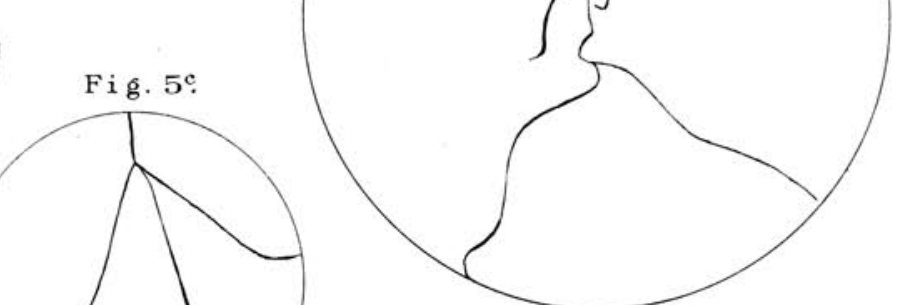

Fig. 6.
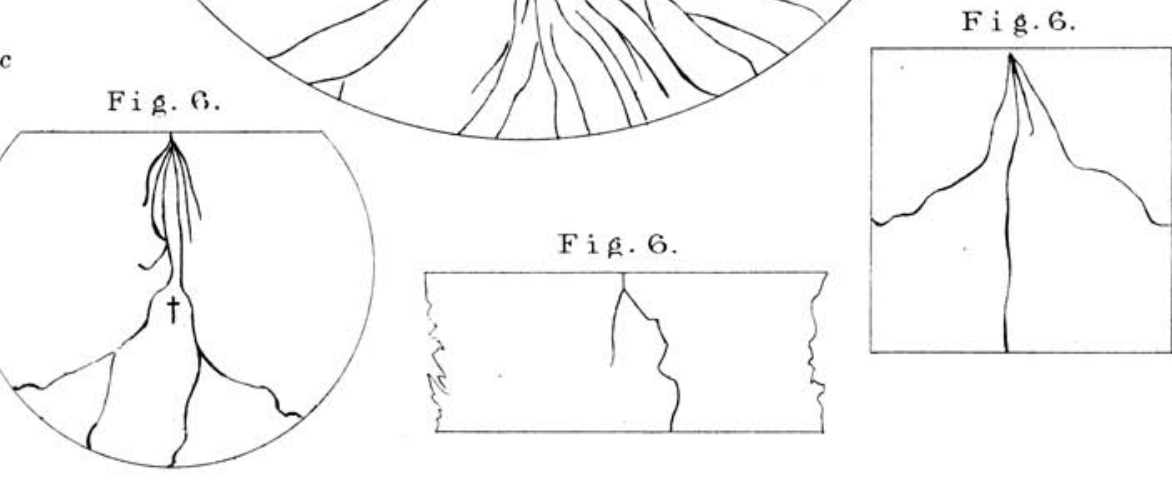
Phil. Maĝ. S. 5. Vol. 8. Pl.III.

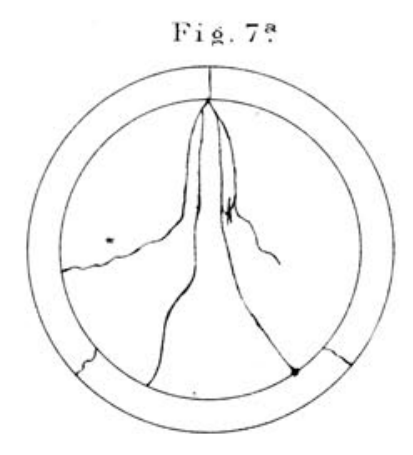

Fig. 7?

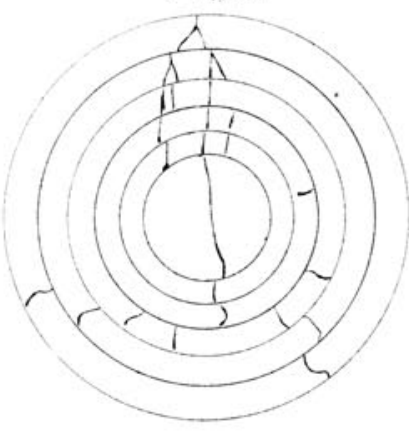

Fig. 8.
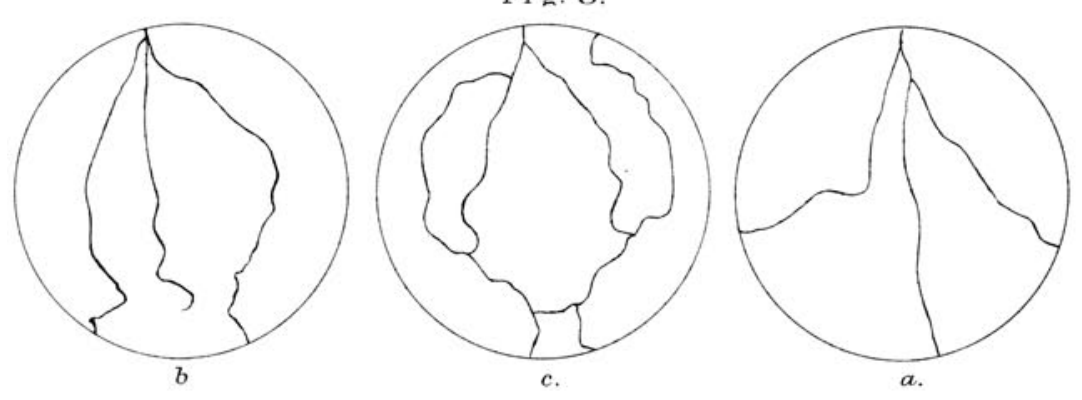

Fig. 9.
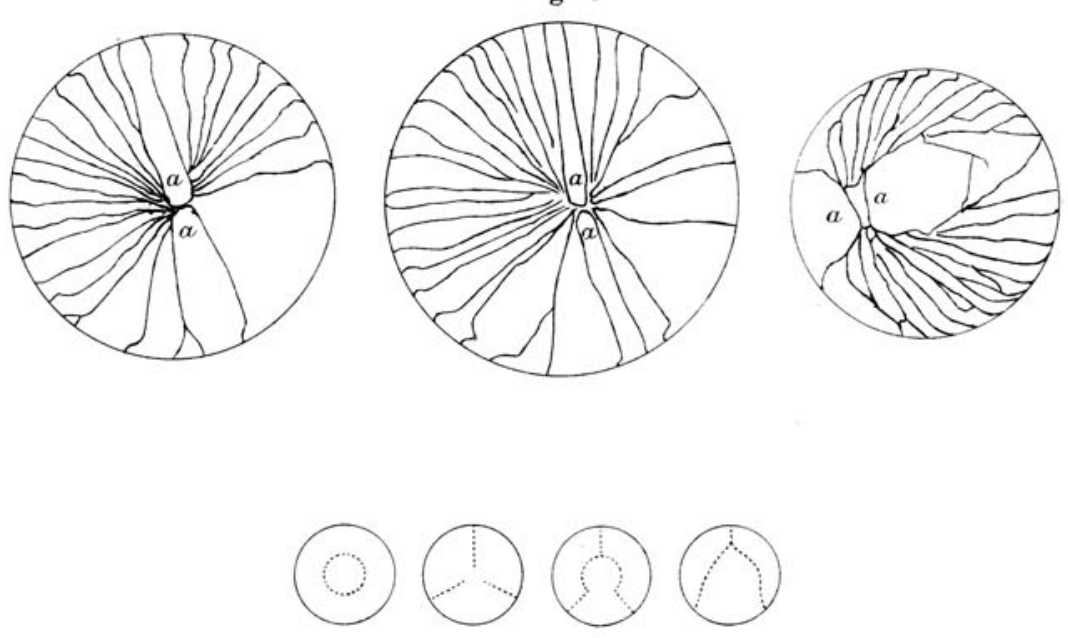

Mintern Bros ith. 